\title{
Les hommes ne peuvent se passer des femmes... ni de leurs hormones
}

En matière de développement sexuel, les données jusqu'à présent étaient fort simples; à chaque sexe, ses hormones: androgènes pour l'homme, œstrogènes pour la femme. Cette notion, communément admise, doit être amendée au plus vite. Car, aussi paradoxal que cela paraisse, il est désormais certain que les hommes ne peuvent impunément se passer d'œstrogènes. Ils les fabriquent à l'aide d'un complexe enzymatique appelé aromatase qui désature l'anneau $\mathrm{A}$ des androgènes pour former un noyau phénolique aboutissant à un œestrogène à 18 carbones $\left(\mathrm{m} / \mathrm{s} \mathrm{n}^{\circ} 3\right.$, vol. $10, p$. 342). L'invalidation par mutation insertionnelle $d u$ gène codant pour le récepteur des oestrogènes chez la souris entraîne, chez les mâles, un défaut de minéralisation squelettique et une oligospermie $(\mathrm{m} / \mathrm{s}$ $n^{\circ} 1$, vol. 11, p. 126) [1]. Deux publications récentes, l'une en clinique humaine rapportant un cas de défaut d'aromatase [2], l'autre par invalidation d'un gène chez la souris [3], viennent enrichir notre connaissance des mécanismes d'action des œestrogènes chez les mâles. Il a été observé que les (rares) sujets masculins qui sont privés d'œestrogènes manifestent des troubles de la maturation osseuse, avec persistance des cartilages de conjugaison et, par conséquent, absence d'arrêt de la croissance, problèmes articulaires et défaut de minéralisation. En outre, ils ont une oligoasthénospermie sévère responsable de stérilité. L'absence d'action œstrogénique peut résulter d'une mutation avec perte de fonction à l'état homozygote, soit dans le gène codant pour les récepteurs des oestrogènes $(\alpha$ et $\beta$ qui sont exprimés dans la plupart des tissus du tractus génital mâle), soit dans le gène codant pour la cytochrome $\mathrm{P} 450$ aromatase qui transforme la testostérone en ostradiol. Alors que l'apport de testostérone est inefficace, le traitement de ces sujets par les œestrogènes stoppe la croissance et améliore la densité osseuse, fournissant ainsi une confirmation supplémentaire du rôle des œestrogènes dans la maturation osseuse pubertaire. Le cas rapporté aujourd'hui présente une mutation de l'aromatase [2]. Le traitement œestrogénique a permis l'évolution du squelette en quelques mois, avec minéralisation et disparition des cartilages de conjugaison. En revanche, l'inefficacité du traitement œestrogénique sur la spermatogenèse chez ce malade avait fait douter du rôle de son déficit œestrogénique dans cette affection. C'est cet aspect des symptômes de déficit en oestrogènes qui vient d'être étudié chez la souris après invalidation du gène $\alpha$ du récepteur œstrogénique [3]. Les souris mâles obtenues (ERKO pour estrogen receptor knock out) sont stériles. Normaux jusqu'à la puberté, leurs testicules s'atrophient à partir de ce moment, avec dilatation des canaux spermatiques et oligospermie. Les canalicules efférents du testicule et l'épididyme sont particulièrement riches en récepteurs des œstrogènes, ce qui a fait chercher dans ces structures le mécanisme responsable de l'infertilité chez les souris ERKO. Le rôle des canalicules n'est pas que de transport des spermatozoïdes: ils sont recouverts d'un épithélium fait de cellules ciliées qui brassent le contenu luminal, et de cellules non ciliées qui réabsorbent environ $90 \%$ du liquide testiculaire. La concentration des spermatozoïdes qui en découle améliore leur survie et leur maturation. Chez les souris ERKO, l'infertilité n'est pas due à un blocage de la spermatogenèse, mais à l'absence de réabsorption du liquide séminal qui se produit normalement dans la tête de l'épididyme et qui est réglée par les œestrogènes; le liquide luminal, non réabsorbé, s'accumule dans les tubes séminifères et les canalicules efférents. L'élévation de la pression liquidienne serait responsable de l'atrophie testiculaire. La preuve expérimentale en a été apportée par la mesure sur canalicule isolé et clos aux deux extrémités de la réabsorption liquidienne et de la surface luminale; (1) la réabsorption liquidienne par les canalicules de souris normales est presque complète en 3 heures et la surface luminale du canalicule diminue de $82 \%$ en 24 heures; (2) la surface des canalicules de souris ERKO augmente de $46 \%$; (3) la surface luminale des canalicules isolés de souris normales traitées pendant 3 jours par des anti-œstrogènes diminue de $14 \%$. Ces derniers ne gonflent pas comme les canalicules des souris ERKO, si bien que le mécanisme d'action des œestrogènes n'est que partiellement compris. Il est possible que le récepteur $\beta$ relaie des actions différentes, mais on ignore encore les effets de l'invalidation de son gène.

Ces résultats qui montrent un effet terminal des œestrogènes laissent encore quelques zones d'ombre quant à la fonction des œestrogènes chez l'homme. Le caractère ubiquitaire des récepteurs des ostrogènes chez l'homme, en particulier dans le système de reproduction, laisse présager des actions biologiques encore insoupçonnées. Ce sujet est d'intérêt, lorsque l'on sait l'importance de l'exposition ostrogénique subie dans certains environnements par les hommes.

S.G.

1. Lubahn DB, Mover JS, Golding TS, Couse JF, Korach KS, Smithies O. Alteration of reproductive function but not prenatal sexual development after insertional disruption of the mouse estrogen receptor gene. Proc Natl Acad Sci USA 1993; 90: 1162-6. 2. Carani C, Qin K, Simoni M, Faustini-Fustini M, Serpente S, Boyd J, Korach KS, Simpson ES. Effect of testosterone and estradiol in a man with aromatase deficiency. N Engl J Med 1997; 337: 91-5.

3. Hess RA, Bunick D, Lee KH, Bahr J, Taylor JA, Korach KS, Lubahn DB. A role for estrogens in the male reproductive system. Nature 1997; 390 : 509-12. 